\title{
SERGIY PETROVYCH OSINSKY (1945-2015)
}

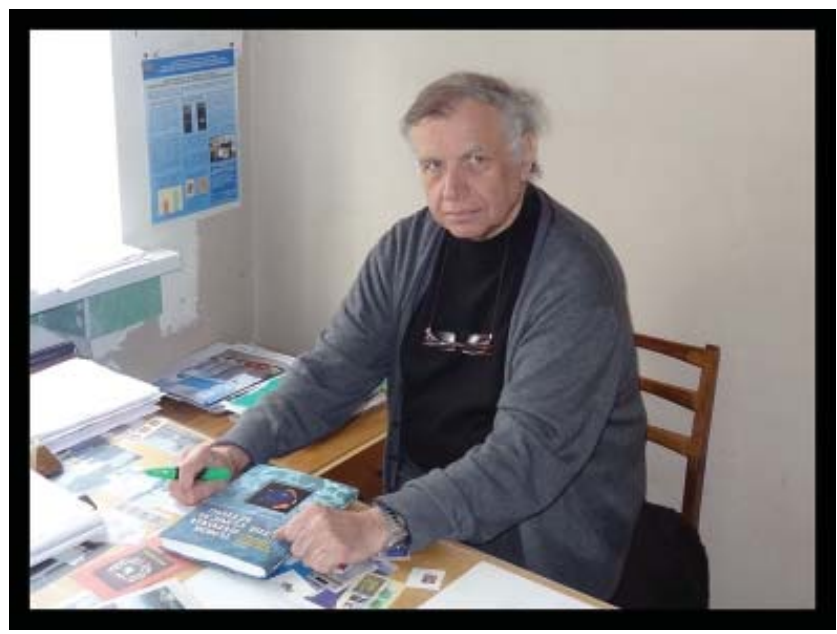

Professor Sergiy Petrovych Osinsky, an outstanding scientist, oncologist and pathophysiologist, Head of Department of the Microenvironment of Tumor Cells of the R.E. Kavetsky Institute of Experimental Pathology, Oncology and Radiobiology (IEPOR) of the NAS of Ukraine, died on May 21, 2015, at the age of 69.

Sergiy Osinsky was born in Mytischy, Moscow region, in the family of doctor. Studying at O.O. Bogomolets Medical Institute in Kyiv, Dr. Osinsky started his research activity at the Institute of Experimental and Clinical Oncology of the Ministry of Health of Ukraine and he adhered to this Institute (now - R.E. Kavetsky IEPOR of the NAS of Ukraine) to the end of his life. In 1973, after his post-graduation study, Dr. Osinsky successfully defended his Ph.D. thesis "Influence of oestrogentherapy on the some indices of metabolism in 7.12-DMBA induced mammary tumors in rats". In 1987, he defended the doctoral thesis "Background of application of induced hyperglycemia for enhancement of anticancer efficacy of chemotherapy and hyperthermia". In 1977-1984, Dr. Osinsky worked as a scientific secretary of R.E. Kavetsky IEPOR of the NAS of Ukraine. In 1993, he was awarded the academic title of professor by the speciality "Oncology".

In 1980 and 1984, Dr. Osinsky worked at Manfred von Ardenne Research Institute (Dresden, DDR). In 1991 and 1993, he had the chance to work in the Department of Pathophysiology headed by Professor Peter Vaupel at the Institute of Physiology and Pathophysiology at the Johannes Gutenberg University of Mainz (Germany). In 2002, he was invited as a Guest Professor to the University La Sapienza (Rome, Italy) in the Department of Chemistry headed by Professor Luigi Campanella.

Prof. Sergiy Osinsky was a scientist with well-established international reputation in the field of tumor pathophysiology. His main areas of interest concerned tumor hypoxia and $\mathrm{pH}$-dependent anticancer modalities, both of which are well known to be important fac- tors in determining tumor response to therapy. He was active in finding clinically applicable methods for modifying tumor microphysiology to enhance the efficacy of subsequent anti-tumor treatment, that is timely, innovative and of interest to the scientific community.

Prof. Osinsky demonstrated that the response of tumors to radiation, chemotherapy or hyperthermia could be enhanced using organocobalt complexes, radiosensitizers like AK-2123 or nicotinamide, inhibitors of DNA repair or cryotreatment. His greatest impact in research was in modifying tumor $\mathrm{pH}$ to improve the therapy outcome. Prof. Osinsky clearly demonstrated that tumor $\mathrm{pH}$ could be decreased by hyperglycemia, either when given alone or when combined with other modalities. With such a decrease in $\mathrm{pH}$, the tumors are sensitized to chemotherapy and/or hyperthermia. The results from his experimental studies have been successfully translated into clinical practice leading to significant improvements in patient survival.

Prof. Osinsky's research activity addressed a number of clinically relevant problems in which appropriate experimental techniques have been used to gain insights into ways in which these problems might be resolved. Together with Prof. Valentyn Ganul, he was the first who initiated the application of microwave hyperthermia in the combined treatment of cancer patients in Ukraine. Prof. Osinsky improved the use of hyperthermia modality in the clinical practice. In recognition of his achievements, he was elected as a member of Consensus Group in Hyperthermia at Kadota Forum (Osaka, June 2004).

Prof. Osinsky was among the few people who could claim that his research is truly translational. His latest research activity was focused on the role of hypoxia in malignant progression, in particular in gastric and pancreatic cancer, the evaluation of significance of hypoxia-regulated proteins as prognostic factors for clinical outcome, and the detection of disseminated cancer cells in peripheral blood and bone marrow in relation to the hypoxic profile of tumors. His studies were supported by the number of international grants (INTAS, SNSF "SCOPES", STCU) and were coordinated by several European research centers.

Prof. Osinsky authored more than 250 scientific papers and 6 monographs, namely "Hyperthermia and hyperglycemia in oncology" (coauthored with E.A. Zhavrid, S.Z. Fradkin, 1987), "Thermophysical models of tumors hyperthermia" (coauthored with A.N. Gusev, V.L. Sigal, 1989), "Tumor cells in peripheral blood and bone marrow of patients with malignant tumors" (coauthored with D.F. Gluzman, V.A. Chernyi, V.V. Lukianchuk, D.S. Osinsky, 2005), "Molecular tumor diagnostics: fundamental bases and 
practical use" (coauthored with D.F. Gluzman, J. Kliff, N.A. Gise, G. Friss, 2007), "Tumor microphysiology" (coauthored with P. Vaupel, 2009), "Tumor hypoxia in the clinical setting" (coeditors H. Friess, P. Vaupel, 2011). He had eight patents for the inventions.

Prof. Osinsky presented his results in many Ukrainian and International scientific meetings, with 65 abstracts having been published in the proceedings of various International scientific forums.

Sergiy Osinsky was a member of several professional societies: International Clinical Hyperthermia Society (ICHS), Indianapolis, USA (a member of the Board of Directors since 1988); European Society of Hyperthermic Oncology (ESHO), Rotterdam, the Netherland (a member of the Board since 2005); British Association of Cancer Research (BACR) since 2003; European Association of Cancer Research (EACR) since 2004.

Prof. Osinsky was a President of the $18^{\text {th }}$ International Symposium of ICHS in 1995 (Kyiv), a Chairman of the International Workshop on applying of hyperthermia as modifying agent in the treatment of cancer patients in 1997 (Kyiv), and Vice-Chairman of the INTAS Workshop "Interdisciplinary Approaches for Cancer Treatment" in 2000 (Kyiv).

Prof. Osinsky was the first winner of R.E. Kavetsky Award of the NAS of Ukraine in 2001.

He served as a Deputy-Editor-in-Chief of "Experimental Oncology" international journal, a mem- ber of Editorial Board of "Oncology" journal and Vice-Chairman in the Specialized Council for Thesis Defense D 26.155.01 on speciality "Oncology" (Kyiv).

All those who had the opportunity to work and communicate with Sergiy Osinsky knew him as a talented creative scientist with a wide range of interests, an intellectual, a fellow capable of listening and understanding the others, being ready to help in a timely manner, a person of the broadest erudition, exceptional honesty and integrity. All the life of Sergiy Osinsky was entirely devoted to selfless service to science, constant search for ways to solve complex problems of oncology. He can rightly be reckoned among those talented scientists who developed the basic ideas of Bogomolets - Kavetsky School of thoughts. Sergiy Petrovych belonged to the category of lucky persons, whose whole life was devoted to the favorite lifework and who had the right to say: "I did everything I could, let others do better". The bright memory of Sergiy Petrovych Osinsky will remain forever in the hearts of all who knew him.

Administration and team

of the R.E. Kavetsky Institute of Experimental Pathology, Oncology and Radiobiology of the NAS of Ukraine

Editorial Board of "Experimental Oncology" 